\title{
Study on Crop Growth Rate and Relative Growth Rate of Growth Analytical Parameters in Wheat, Barley and Oat
}

\author{
Deepika Verma $^{1 *}$, Ompal Singh ${ }^{1}$, Anita Deshmukh ${ }^{2}$ and A.S. Gontia ${ }^{1}$ \\ ${ }^{1}$ Department of Plant Physiology, JNKVV, Jabalpur, India \\ ${ }^{2}$ Department of Extension, Dr PDKV, Akola, India \\ *Corresponding author
}

\section{A B S T R A C T}

\begin{tabular}{|l|}
\hline Ke y w or d s \\
$\begin{array}{l}\text { Wheat, Oat, Barle } \\
\text { leaf area index and } \\
\text { leaf area duration. }\end{array}$ \\
\hline Article Info \\
\hline $\begin{array}{l}\text { Accepted: } \\
\text { 19 July } 2017 \\
\text { Available Online: } \\
\text { 10 September } 2017\end{array}$
\end{tabular}

Keywords

Wheat, Oat, Barle leaf area index and leaf area duration.

mber 2017
An experiment was conducted in rabi season during 2012-2013 and 20132014 to find out the effect of cereal crops (Wheat, Oat, Barley) and cutting schedule on forage and grain yield. The study revealed the maximum chlorophyll accumulation in Barley and wheat during initial stage at 95 DAS and wheat and barley during reproductive stage at 30 DAS. Cutting at 50 DAS is proved beneficial on chlorophyll accumulation. Photosynthetic rate were maximum in wheat at 90 DAS. However cutting did not affect photosynthesis rate stomatal conductance and transpiration rate. Barley gave maximum fodder yield (fresh/day). Cutting at 50 DAS was beneficial in producing maximum fodder yield without sacrificing grain yield of cereal crops.

\section{Introduction}

Wheat (Triticum aestivum), Oat (Avena sativa L.) and Barley (Hordeum vulgare L.) are the cereal crops of the world in general and India in particular. India ranks second in wheat, fifth in oat, fourth in barley. Wheat is the most important staple food grain in India (70 million tons per year).Owing to vareatizle ecological adaptability barley is the second largest producing crop cereal crop of winter season in India. Oat is mainly used as fodder crop in the world with legume fodder as compared to food grain crop. In the recent years, it has been observed that because of severe drought in the drier of northern plains (Rajasthan, Southern Haryana, Western U.P. and Madhya Pradesh), there is an acute shortage of green fodder in the months of November to January. Barley can be utilized as a source of green fodder under such situations. The crop can be given one cut at definite time after sowing for green fodder and regeneration crop may be utilized for grain purpose. Oats (Avena sativa L.) rank fifth (Dost, 1997) in terms of world production of cereals. They are also widely used as a companion crop for under-seeding of forage legumes The average green yield of local cultivars (tall with very narrow leaves and thin stems, hence, not responsive to nitrogenous fertilizers due to lodging) under 
rain fed conditions is 20 tons/ha, which is very low and insufficient to provide even maintenance rations for the numbers of livestock kept. In winter farmers have only dried summer grass or dry stalks of summer cereals to supplement the small amount of forage grown and have to purchase costly fodder transported in large quantities from distant irrigated tracts.

In contrast to local landraces, improved oats grow very fast, can be cut earlier and have considerable potential to provide feed during deficit periods and low temperatures. Generally, farmers harvest these fodders at 50 percent flowering, or at a later stage to get maximum green yield with a consequent loss in quality. The productivity of a crop stand depends on its capacity of photosynthesis, photosynthetic area and the utilization of photosynthetic active radiation within the crop canopy. In graminaceous crops, the grain yield is a product of grain weight per ear and number of ear per unit area.

Chlorophyll is vital for photosynthesis, which allows plants to absorb energy from light. Chlorophyll content is an index of organic matter production and plant growth. The increased photosynthesis has been linked to increased chlorophyll content in plants. As a result, chlorophyll content is a measurement of physiological activities in plants. Abiotic stress is a major factor around the world in limiting plant growth and productivity. Exposure of plants to a stressful environment during various developmental stages appears to induce various physiological and developmental changes.

Indian dairy industry is facing a lot of shortage of green forage during winter and summer seasons especially in terms of cereal forage. Hence the present experiment was conducted to find out suitable cereal crop for rabi season by cutting existing crop once and then crop grown for food grain production without reducing food grain productivity. Physiological traits like chlorophyll index, photosynthetic rate, stomatal conductance and transpiration rate were used as parameters to judge the suitability of cereal crops for fodder and grain production with reference to central India.

\section{Materials and Methods}

The present investigation was carried out at the experimental field of All India CoOrdinated Research Project on forage crops, Live Stock Farm, Department of Agronomy, College of Agriculture, JNKVV, Jabalpur (M.P.) during the rabi season 2012-13 in a Spilt Plot Design (SPD), replicated thrice. The experimental material consisted of 3 cereal crops viz.; (VL829), Oat (RD2552), Barley (JO1) as main plot treatments and 4 cutting dates i.e. no cutting wheat, single cutting at 50 days after sowing (DAS), single cutting 60 (DAS) and single cutting at 70 (DAS) respectively as sub plot treatment. Growth parameters studied were leaf area index (LAI) at 45, 60, 75, 90 and 105 DAS), and leaf area duration at 45, 60, 75, 90 and 105 DAS), the leaf area index was determined as per specifications and LAD expresses the magnitude and persistence of leaf area of leafiness during the period of crop growth. It reflects the extent or seasonal integral of light interception and correlates with yield. Fischer's method of analysis of variance was applied for the analysis of the data the level of significance used in $\mathrm{F}$ and $\mathrm{t}$ test was $\mathrm{P}=0.05$ critical difference (CD) values were calculated at 5 per cent probability level, wherever $\mathrm{F}$ test was significant.

\section{Results and Discussion}

\section{Crop growth rate (CGR)}

The results showed that the Barely (0.0002667) dominated others crops for CGR. Oat registered the lowest (0.0001633) 
magnitude for this trait and in sub treatments $\mathrm{C}_{1}(0.00027)$ significant superseded others for CGR. The significant lowest magnitude was noted in $\mathrm{C}_{4}$ (0.00018).In interactions, $\mathrm{BC}_{1}$ (0.00031) at par with $\mathrm{WC}_{1}(0.0028)$ had significant more CGR over rest of the interactions. The lowest value $(0.00011)$ was recorded in $\mathrm{OC}_{4}$. At 40 days. The study revealed that Barely (0.00057) dominated others crops for CGR Oat registered the lowest (0.00032) magnitude for this trait at 60 days and also sub treatments, $\mathrm{C}_{1}(0.00049)$ significant superseded others for CGR. The significant lowest magnitude was noted in $\mathrm{C}_{4}$ (0.00039).In interactions $\mathrm{BC}_{1} \quad$ (0.00028) possessed the significant maximum and minimum values for this character at 60 days. At the 75 days result of the study showed that Barely (0.0015) significantly dominated others crops for CGR Oat registered the lowest (0.00091). And in sub treatments, $C_{1}$ (0.0012) and $\mathrm{C}_{4}(0.0010)$ possessed the significant maximum values for this character and in interaction, $\mathrm{BC}_{1}(0.0012)$ and $\mathrm{BC}_{2}$ (0.0014) registered significant more CGR over rest of the interactions. The lowest value was noted in $\mathrm{OC}_{4}(0.00085)$. The results revealed that at 90 days Barely crop (0.00033) dominated others crops for CGR. Oat registered the lowest (0.00020) magnitude for this trait. Among sub treatments, $\mathrm{C}_{1}(0.00031)$ and $\mathrm{C}_{4}(0.00021)$ possessed and $\mathrm{C}_{4}(0.00021)$ possessed the significant maximum and minimum values for this character. In interactions, $\mathrm{BC}_{1}(0.00040)$ at par with $\mathrm{BC}_{2}$ (0.00036) had significant more CGR over rest of the interactions. The lowest value (0.00016) was found in $\mathrm{OC}_{4}$. The result revealed that Barely (0.00017) significant dominated over rest for CGR. Oat registered the lowest (0.00096). Among sub treatments $\mathrm{C}_{1}(0.00016)$ and $\mathrm{C}_{4}(0.00010)$ possessed the significant maximum and minimum values for this character. In interactions, $\mathrm{BC}_{1}(0.00020)$ and maximum and minimum values for CGR at 105 days (Table 1).

\section{CGR (pooled)}

The results pertaining to the study of crop growth rate indicated significant difference among main treatments at 45, 60, 75, 90, and 105 DAS and average and interactions at 45, 60, 75 and 90 DAS and average and interactions at 45, 60, 90, and 105 DAS and average. However in remaining period the treatments and interactions did not differ significant polled analysis and at 45 DAS the results showed that wheat $(0.0003)$ dominated others crops for CGR. Oat registered the lowest (0.0002) magnitude for this character. Among sub treatment, $\mathrm{C}_{1}(0.0067)$ superseded others sub treatments for the same character $\mathrm{C}_{4}$ registered the lowest value. In interaction $\mathrm{WC}_{1}(0.003)$ and $\mathrm{WC}_{2}(0.000$.) registered significant more CGR over rest of the interactions. The lowest CGR was recorded on $\mathrm{OC}_{4}(0.001)$ and result on pooled at 60 DAS revealed that Barely crop (0.0006) possessed significant higher CGR over rest of the crops. Oat registered the lowest (0.0003). Among sub treatments, $\mathrm{C}_{1}$ (0.0005) superseded others sub treatments for CGR. The lowest value $(0.0004)$ was found in $\mathrm{C}_{4}$.In interactions, $\mathrm{BC}_{1}(0.0006)$ had significant more CGR over rest of the interactions. Though $\mathrm{BC}_{2}$ (0.0006) lagged behind the former but showed significant superiority over rest of the interactions except $\mathrm{WC}_{1}$ and $\mathrm{BC}_{4}$. The lowest value $(0.0003)$ was found in $\mathrm{OC}_{3}$ and at 75 DAS the study showed that Barely crop (0.0015) significant dominated lowest (0.0009) magnitude for this character. Among sub treatments, $\mathrm{C}_{1}(0.0012)$ and $\mathrm{C}_{2}$ (0.0012) possessed higher CGR over others sub treatments. $\mathrm{C}_{4}(0.0011)$ recorded the lowest value for this character though was at par with $\mathrm{C}_{3}$.In sub treatment, $\mathrm{BC}_{1}(0.0016)$ and $\mathrm{BC}_{2}(0.0015)$ registered significant more CGR over rest of the interactions. The lowest value was recorded in $\mathrm{OC}_{2}(0.0009)$ and at 90 DAS the results exhibited that wheat (0.0003) had the highest CGR over rest of the main 
treatments. Oat noted the significant lowest (0.0002) among sub treatments, $C_{1}(0.0003)$ superseded others sub treatments for the same character. The lowest magnitude was noted in $\mathrm{C}_{4}$ (0.0002).In interactions, $\mathrm{BC}_{1}(0.0004)$ at par with $\mathrm{BC}_{2}(0.0004)$ had significant more CGR over rest of the interactions. The lowest value (0.0002) was found in $\mathrm{OC}_{2}$ and at 105 DAS the results revealed that Barely (0.0002) significant other crop for CGR. Oat registered the lowest value (0.0001).Among sub treatments, $\mathrm{C}_{1} \quad(0.0002)$ significantly superseded other sub treatment for the same trait. $\mathrm{C}_{4}$ had the lowest (0.0001).In interactions, (0.0006) and $\mathrm{OC}_{3}$ (0.0003) maximum and minimum values for this character (Table 1).

\section{Relative growth rate (g/g/day)}

The results pertaining to the study RGR indicated significant differences among main and Sub treatments. Interaction, during 90105 DAS for both the years were not significant. The results showed that Oat (0.0320) significantly dominated over others for RGR. Wheat registered the lowest (.0083) magnitude. Among sub treatments $\mathrm{C}_{3}$ (0.0325) among main treatments superseded other sub treatments for RGR. The significant lowest magnitude was noted in $\mathrm{C}_{4}$ (0.009).In interactions of $\mathrm{WC}_{4}(.0038)$ and $\mathrm{OC}_{3}(0.0038)$ registered significant more RGR over rest of the interactions. The lowest RGR was recorded in $\mathrm{WC}_{3}(0.0038)$ at $45 \mathrm{DAS}$ and at 60 DAS investigations revealed showed (Table 2) that crop Wheat indicated significant highest (0.0116) and Oat significant lowest (0.0032) RGR among main treatments. Among sub treatments $\mathrm{C}_{1}$ (0.0088) significantly superseded other sub treatments for RGR. $\mathrm{C}_{4}$ had the significant lowest (0.0026) RGR. In interactions $\mathrm{WC}_{3}$ (0.0186) and $\mathrm{WC}_{1}(0.0161)$ had significant more RGR over rest of the interactions. The lowest value (0.0024) was found in $\mathrm{OC}_{4}$ and at 75 DAS the results showed (Table 2) that Barley crop (0.0334) significantly dominated other crops for RGR. Wheat registered the significant lowest (0.0233) magnitude for this character. In sub treatments $\mathrm{C}_{1}$ (0.0324) significantly superseded other sub treatments for RGR. $\mathrm{C}_{3}$ had the lowest (0.028) RGR. Interactions of $\mathrm{BC}_{4}(0.0367)$ and $\mathrm{OC}_{1}$ (0.0352) registered significant more RGR over rest of the interactions. The lowest RGR was recorded in $\mathrm{WC}_{4}(0.0186)$ and at $90 \mathrm{DAS}$ Investigations reveled showed (Table 2) that crop wheat indicated significant highest (0.0233) and Oat significant lowest (0.013) RGR among crops treated as main treats. In sub treatments $\mathrm{C}_{4}(0.0250)$ and $\mathrm{C}_{3}(0.0233)$ possessed the maximum and minimum values for RGR. In interactions $\mathrm{WC}_{2}(0.0328)$ and $\mathrm{WC}_{1}$ (0.0314) had registered significant more RGR over rest of the interactions. The lowest value (0.0117) was found in $\mathrm{OC}_{4}$.

At 105 DAS the results indicated (Table 2) that among treatments and interactions wheat (0.009) and Oat (0.003) in main treatments $C_{1}$ (0.007) and $\mathrm{C}_{2}$ (0.006) in sub treatments and $\mathrm{WC}_{1}(0.013)$ and $\mathrm{BC}_{4}(0.001)$ in interactions recorded the maximum values for this parameter, respectively and relative growth in year 2013-14 at 45 DAS Investigations indicated that Wheat indicated highest (0.0042) and Oat registered significant lowest (0.003) RGR among main treatments (Table 2). Among sub treatments $\mathrm{C}_{1} \quad(0.0053)$ superseded other sub treatments for RGR. The significant lowest magnitude was noted in $\mathrm{C}_{4}$ (0.0036).In interactions $\mathrm{WC}_{1}(0.0075)$ and $\mathrm{WC}_{3}(0.0070)$ had significant more RGR over rest of the interactions. The lowest value (0.0032) was found in $\mathrm{OC}_{4}$. At 60 DAS the results showed (Table 2) that Barley crop (0.0051) significantly dominates other crop for CGR. Oat registered the lowest (0.0037) RGR among main treatments. 
Table.1 Crop growth rate $\left(\mathrm{g} / \mathrm{cm}^{2} / \mathrm{day}\right)$ in different and interactions at successive growth intervals

\begin{tabular}{|c|c|c|c|c|c|c|}
\hline Main treatments & 45 DAS & 60 DAS & 75 DAS & 90 DAS & 105 DAS & AVERAGE \\
\hline $\mathrm{W}$ & 0.0003 & 0.0004 & 0.0010 & 0.0003 & 0.0001 & 0.0004 \\
\hline $\mathrm{O}$ & 0.0002 & 0.0003 & 0.0009 & 0.0002 & 0.0001 & 0.0003 \\
\hline B & 0.0003 & 0.0006 & 0.0015 & 0.0003 & 0.0002 & 0.0006 \\
\hline Sem \pm & 5.7720 & 0.8300 & 3.5550 & 2.4050 & 3.1000 & 3.1324 \\
\hline C.D. $5 \%$ & 5.6600 & 6.5415 & 3.2500 & 0.9400 & 4.7000 & 4.2183 \\
\hline \multicolumn{7}{|l|}{ Sub treatments } \\
\hline $\mathrm{C}_{1}$ & 0.0003 & 0.0005 & 0.0012 & 0.0003 & 0.0002 & 0.0005 \\
\hline $\mathrm{C}_{2}$ & 0.0003 & 0.0005 & 0.0012 & 0.0003 & 0.0001 & 0.0005 \\
\hline $\mathrm{C}_{3}$ & 0.0002 & 0.0004 & 0.0011 & 0.0003 & 0.0001 & 0.0004 \\
\hline $\mathrm{C}_{4}$ & 0.0002 & 0.0004 & 0.0011 & 0.0002 & 0.0001 & 0.0004 \\
\hline Sem \pm & 5.3445 & 5.8615 & 2.6000 & 2.1350 & 5.7450 & 4.3372 \\
\hline C.D.5\% & 0.0000 & 0.8150 & 0.0000 & 0.0000 & 0.0000 & 0.1630 \\
\hline \multicolumn{7}{|l|}{ Interactions } \\
\hline $\mathrm{WC}_{1}$ & 0.0003 & 0.0005 & 0.0012 & 0.0003 & 0.0002 & 0.0005 \\
\hline $\mathrm{WC}_{2}$ & 0.0003 & 0.0004 & 0.0011 & 0.0003 & 0.0001 & 0.0004 \\
\hline $\mathrm{WC}_{3}$ & 0.0002 & 0.0004 & 0.0010 & 0.0003 & 0.0001 & 0.0004 \\
\hline $\mathrm{WC}_{4}$ & 0.0002 & 0.0004 & 0.0009 & 0.0003 & 0.0001 & 0.0004 \\
\hline $\mathrm{OC}_{1}$ & 0.0002 & 0.0004 & 0.0010 & 0.0002 & 0.0001 & 0.0004 \\
\hline $\mathrm{OC}_{2}$ & 0.0002 & 0.0003 & 0.0009 & 0.0002 & 0.0001 & 0.0004 \\
\hline $\mathrm{OC}_{3}$ & 0.0001 & 0.0003 & 0.0009 & 0.0002 & 0.0001 & 0.0003 \\
\hline $\mathrm{OC}_{4}$ & 0.0001 & 0.0003 & 0.0009 & 0.0002 & 0.0001 & 0.0003 \\
\hline $\mathrm{BC}_{1}$ & 0.0003 & 0.0006 & 0.0016 & 0.0004 & 0.0002 & 0.0006 \\
\hline $\mathrm{BC}_{2}$ & 0.0003 & 0.0006 & 0.0015 & 0.0004 & 0.0002 & 0.0006 \\
\hline $\mathrm{BC}_{3}$ & 0.0003 & 0.0006 & 0.0015 & 0.0003 & 0.0002 & 0.0006 \\
\hline $\mathrm{BC}_{4}$ & 0.0002 & 0.0005 & 0.0014 & 0.0003 & 0.0001 & 0.0005 \\
\hline Sem \pm & 4.6304 & 2.3570 & 2.2568 & 1.8500 & 5.0030 & 3.2194 \\
\hline C.D. $5 \%$ & 0.0000 & 0.6850 & 0.0012 & 0.0000 & NS & 0.1716 \\
\hline
\end{tabular}

Table.2 Relative growth rate (g/g/day) in treatments and interactions at successive life span (pooled)

\begin{tabular}{|c|c|c|c|c|c|c|}
\hline Main treatments & 45 DAS & 60 DAS & 75 DAS & 90 DAS & 105 DAS & AVERAGE \\
\hline $\mathrm{W}$ & 0.0062 & 0.0084 & 0.0183 & 0.0135 & 0.0061 & 0.011 \\
\hline $\mathrm{O}$ & 0.0178 & 0.0177 & 0.0177 & 0.0080 & 0.0047 & 0.013 \\
\hline B & 0.0104 & 0.0056 & 0.0189 & 0.0157 & 0.0032 & 0.011 \\
\hline Sem \pm & 0.0015 & 0.0025 & 0.0004 & 0.0026 & 0.0024 & 0.002 \\
\hline C.D. $5 \%$ & 0.0060 & 0.0031 & 0.0015 & 0.0048 & 0.0016 & 0.003 \\
\hline \multicolumn{7}{|l|}{ Sub treatments } \\
\hline $\mathrm{C}_{1}$ & 0.0083 & 0.0067 & 0.0189 & 0.0146 & 0.0042 & 0.011 \\
\hline $\mathrm{C}_{2}$ & 0.0128 & 0.0065 & 0.0169 & 0.0142 & 0.0042 & 0.011 \\
\hline $\mathrm{C}_{3}$ & 0.0183 & 0.0045 & 0.0164 & 0.0118 & 0.0032 & 0.011 \\
\hline $\mathrm{C}_{4}$ & 0.0064 & 0.0016 & 0.0160 & 0.0128 & 0.0037 & 0.008 \\
\hline Sem \pm & 0.0024 & 0.0005 & 0.0006 & 0.0011 & 0.0007 & 0.001 \\
\hline C.D. $5 \%$ & 0.0070 & 0.0019 & 0.0016 & 0.0005 & 0.0005 & 0.002 \\
\hline \multicolumn{7}{|l|}{ Interactions } \\
\hline $\mathrm{WC}_{1}$ & 0.0041 & 0.0108 & 0.0173 & 0.0175 & 0.0096 & 0.012 \\
\hline $\mathrm{WC}_{2}$ & 0.0046 & 0.0072 & 0.0158 & 0.0183 & 0.0071 & 0.011 \\
\hline $\mathrm{WC}_{3}$ & 0.0039 & 0.0117 & 0.0136 & 0.0175 & 0.0028 & 0.010 \\
\hline $\mathrm{WC}_{4}$ & 0.0034 & 0.0039 & 0.0112 & 0.0158 & 0.0050 & 0.008 \\
\hline $\mathrm{OC}_{1}$ & 0.0035 & 0.0044 & 0.0198 & 0.0075 & 0.0043 & 0.008 \\
\hline $\mathrm{OC}_{2}$ & 0.0037 & 0.0029 & 0.0170 & 0.0071 & 0.0035 & 0.007 \\
\hline $\mathrm{OC}_{3}$ & 0.0038 & 0.0033 & 0.0174 & 0.0074 & 0.0055 & 0.007 \\
\hline $\mathrm{OC}_{4}$ & 0.0038 & 0.0031 & 0.0167 & 0.0100 & 0.0056 & 0.008 \\
\hline $\mathrm{BC}_{1}$ & 0.0040 & 0.0056 & 0.0195 & 0.0172 & 0.0024 & 0.010 \\
\hline $\mathrm{BC}_{2}$ & 0.0042 & 0.0082 & 0.0177 & 0.0152 & 0.0030 & 0.010 \\
\hline $\mathrm{BC}_{3}$ & 0.0042 & 0.0052 & 0.0180 & 0.0152 & 0.0033 & 0.009 \\
\hline $\mathrm{BC}_{4}$ & 0.0039 & 0.0038 & 0.0203 & 0.0182 & 0.0018 & 0.010 \\
\hline Sem \pm & 0.0021 & 0.0004 & 0.0006 & 0.0009 & 0.0006 & 0.001 \\
\hline C.D. $5 \%$ & 0.0059 & 0.0016 & 0.0014 & 0.0004 & 0.0004 & 0.002 \\
\hline
\end{tabular}


Among sub treatments $\mathrm{C}_{2} \quad(0.0045)$ superseded others sub treatments for RGR the significant lowest magnitude was noted in $\mathrm{C}_{4}$ (0.0036). In interactions $\mathrm{WC}_{2}$ had significant more RGR over rest of the interactions. Though $\mathrm{BC}_{3}$ (0.0046) lagged behind the former but showed significant superiority over rest of the interaction except $\mathrm{WC}_{1}, \mathrm{BC}_{2}$ and $\mathrm{BC}_{1}$. The lowest value was found in $\mathrm{WC}_{4}$ (0.0030) and at 75 DAS Investigations revealed showed that crop Barley indicated highest (0.0043) and Wheat (0.0029) though they were at par between them Oat indicated lowest (0.0020) RGR among main treatments. Among sub treatments $\mathrm{C}_{2} \quad$ (0.0025) significantly superseded other sub treatments for RGR. $\mathrm{C}_{3}$ had the lowest (0.0002) RGR thought was at par with $\mathrm{C}_{3}(0.0002)$ in interactions $\mathrm{WC}_{1}(0.0066)$ and $\mathrm{WC}_{2}(0.0044)$ had significant more RGR over rest of the interactions. The lowest value (0.0001) was found in $\mathrm{WC}_{4}$ and at 90 DAS the results showed (Table 2) that Wheat crop (0.0037) significantly dominated other crops for RGR.

Oat registered the significant lowest (0.0026) magnitude for RGR. Among sub treatments $\mathrm{C}_{2}(0.0049)$ and $\mathrm{C}_{1}(0.0044)$ possessed higher CGR over rest over others sub treatments $C_{3}$ (0.002) recorded the lowest value for this character though was at par with $\mathrm{C}_{1}$.In interactions $\mathrm{BC}_{1}(0.0051), \mathrm{BC}_{4}(0.0051), \mathrm{BC}_{2}$ (0.0047) and $\mathrm{BC}_{3}(0.0047)$ recorded significant higher CGR over rest of the treatments $\mathrm{OC}_{1}(0.0016)$ was associated with the minimum magnitude for this trait and at 45 DAS the results showed (Table 2) that Wheat crop (0.0029) significantly dominate other crop for RGR. Oat registered the significant lowest (0.0020) magnitude for RGR. In sub treatments $C_{2}(0.0054)$ and $C_{3}$ (0.0002) possessed the maximum and minimum values for RGR. In interactions of crop cuttings indicated that treatment combinations $\mathrm{BC}_{1}(0.0060)$ and $\mathrm{WC}_{1}(0.0055)$ registered significant more RGR over rest of the interactions. The lowest RGR was recorded in OC2 (0.0034).

\section{RGR (g/g/day), pooled}

The result exhibited (Table 2) that the oat (0.0178) maximum and minimum value for RGR. Among sub treatment, $\mathrm{C}_{3}(0.0183)$ superseded other sub treatment for the same traits. The lowest value (0.0064) was found in $\mathrm{C}_{4}$ at 45 DAS and at 60 DAS the results indicated (Table 2) that oat crop (0.0177) significant superseded others for RGR and barely registered the lowest value (0.0056). Among sub treatment $\mathrm{C}_{1}(0.0067)$ supersede other sub treatments for the same character. $\mathrm{C}_{4}$ (0.0016) the registered the lowest value. In interaction $\mathrm{WC}_{3}(0.0117)$ at par with $\mathrm{WC}_{1}$ (0.0108) had significant more RGR over rest of the interaction. The lowest value (0.0029) was found in $\mathrm{OC}_{2}$ and at 75 DAS the result showed (Table 2) that barely crop (0.0189) dominated other crops for RGR. Oat registered the lowest $(0.177)$ magnitude for this trait. Among sub treatments $C_{1}$ (0.0189) superseded other sub treatment for the same character. The lowest magnitude was noted in $\mathrm{C}_{4}$ (0.0160). In interaction, $\mathrm{BC}_{4}(0.0203)$ registered significant more RGR over rest of the interactions. The lowest value (0.0112) was recorded in $\mathrm{WC}_{4}$.and at 90 DAS the result reveled (Table 2) that barely (0.0157) possessed the higher RGR over rest of the main treatment oat registered the significant lowest (0.0080) magnitude among main treatments. Among sub treatments $\mathrm{C}_{1}$ (0.0146) superseded other sub treatment for the same trait $\mathrm{C}_{2}$ had the lowest value (0.0118) in interactions, $\mathrm{WC}_{2}(0.0183)$ at par with $\mathrm{BC}_{4}(0.0182)$ had significant more RGR over rest of the interaction. The lowest value (0.0071) was found in $\mathrm{OC}_{3}$. and at $105 \mathrm{DAS}$ the result showed (Table 2) that wheat (0.0061) had the highest RGR over rest of the main treatment barley noted the significant lowest (0.0032). Among sub treatments, $\mathrm{C}_{1}$ 
(0.0042) significant superseded other sub treatment for RGR. $\mathrm{C}_{3}$ had the lowest (0.0032). In interactions, $\mathrm{WC}_{1}(0.0096)$ and $\mathrm{BC}_{1}(0.0018)$ possessed the significant maximum and minimum values for this character.

Thus the study revealed (T, F) that the CGR in treatments and interactions increased with the age, attaining the peak at 75 DAS, therefore it decline in sub sequent growth period. Among main treatments, barely recorded the average maximum CGR (0.0006), followed by wheat (0.0004). In sub treatments $\mathrm{C}_{1}$ and $\mathrm{C}_{2}(0.0005)$ recorded the higher magnitude. On the others hand in interactions $\mathrm{BC}_{1}, \mathrm{BC}_{2}$ and $\mathrm{BC}_{3}(.0006)$ were found to be associated with the higher magnitudes for this character.

The study showed that the RGR starts increasing magnitudes from early growth phase onwards, recording the peak between 75 and 90 DAS, followed by a subsequent decline in rest of the growth period. Oat recoded an average higher RGR (0.013) in main treatments. In sub treatments except $\mathrm{C}_{4}$ all others possessed the same magnitude (0.011). In interactions $\mathrm{WC}_{1}(0.012)$ and $\mathrm{WC}_{2}$ $(0.011)$ were found to be associated with the maximum values for this character.

\section{References}

Burman, U., Garg BK, Yadav OP and Kathju S. 2011. Effect of terminal water stress on growth, plant water status and yield of pearl millet genotypes. Indian Journal of Plant Physiology, 16(3-4): 276-284.

Cash, S.D., Surber LMM, Wichman DM and Hensleigh PF. 2008. Forage yield, quality and nitrate concentration of barley grown under irrigation. Montana State University Extension Service. Bozeman, USA

Karimi, M.M., and Siddique KHM. 1991. Crop growth and relative growth rates of oil and modern wheat cultivars. Australian Journal of Agricultural Research, 42(1):13-20.

Singh, J., Singh SK, Kausar F and Kumar R. 2002. Study of relationship between yield and its contributing characters in wheat. Progressive Agriculture, 2(2):88-89.

Spitter, C.J.T., and Krammer Th. 2005. Changes in relative growth rate with plant ortogony in spring wheat genotypes grower as isolated. Plant Journal of Euphytica, 34(3):833-847.

\section{How to cite this article:}

Deepika Verma, Ompal Singh, Anita Deshmukh and Gontia, A.S. 2017. Study on Crop Growth Rate and Relative Growth Rate of Growth Analytical Parameters in Wheat, Barley and Oat. Int.J.Curr.Microbiol.App.Sci. 6(9): 1341-1347. doi: https://doi.org/10.20546/ijcmas.2017.609.162 